\title{
Distribuição da \\ Força de Trabalho: eqüidade e negociação
}

I ${ }^{1}$ Vera Regina da Silva Miguelote, ${ }^{2}$ Maria Thereza Fortes, ${ }^{3}$ Marise Fagundes, ${ }^{4}$ Thereza Christina Varella I

Resumo: A enorme desproporção na densidade de recursos humanos - existente entre os países da África e o resto do mundo - coloca a questão da eqüidade na distribuição da força de trabalho como destaque estratégico para a resolução dos problemas de saúde. Daí a relevância do tema recursos humanos na agenda política global e nas prioridades para o setor saúde. A política de captação e recrutamento por parte dos países desenvolvidos, associada à ausência de políticas claras, nos países em desenvolvimento, contribui para o aumento da migração. Algumas agências internacionais, sob a liderança da Organização Mundial da Saúde (OMS), têm-se destacado na definição ou desenvolvimento de políticas de recursos humanos em saúde (RHS). No entanto, a existência de um paradoxo entre a interdependência e a soberania dos países requer um posicionamento ético estratégico, no sentido de fortalecer as nações em suas transações comerciais. Assim, um dos desafios para a saúde global está em aproveitar o potencial de articulação oferecido pelo General Agreement on Trade in Services (GATS), para as negociações internacionais de RHS.

Palavras-chave: Eqüidade; distribuição mundial de RHS; migração da força de trabalho em saúde; negociação internacional; GATS.

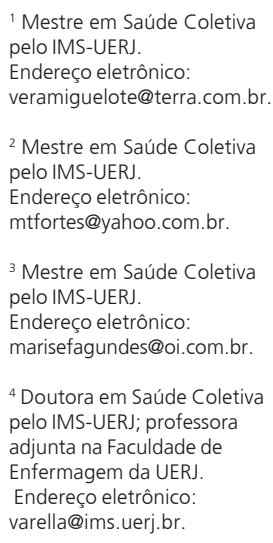

${ }^{3}$ Mestre em Saúde Coletiva pelo IMS-UERJ. Endereço eletrônico: marisefagundes@oi.com.br.

${ }^{4}$ Doutora em Saúde Coletiva pelo IMS-UERJ; professora adjunta na Faculdade de Enfermagem da UERJ. Endereço eletrônico: varella@ims.uerj.br. 


\section{Introdução}

As metas de desenvolvimento para o novo milênio e as prioridades do setor saúde para a próxima década trazem a questão da eqüidade na distribuição da força de trabalho como destaque estratégico para a resolução dos problemas de saúde. A partir da evidência de uma enorme desproporção na densidade de recursos humanos, entre os países da África e o resto do mundo, este trabalho aborda o problema na perspectiva internacional, destacando, em primeiro lugar, a relevância do tema recursos humanos na agenda política global.

Em segundo, estudamos a densidade da força de trabalho em saúde no mundo atual, contextualizando e problematizando as desigualdades, o desequilíbrio e a migração internacional de profissionais de saúde, ressaltada como um dos principais geradores do grave desequilíbrio existente. Em seguida, situamos as razões atuais desse movimento migratório e sua relação com a baixa densidade de RHS nos países em desenvolvimento.

O quarto tópico enfoca o papel atual das organizações internacionais - as criadas a partir das Nações Unidas e aquelas formadas a partir do acordo de Bretton Woods - na definição e desenvolvimento de políticas de recursos humanos em saúde. A seguir, analisamos as regras da Organização Mundial do Comércio (OMC) para liberalização do comércio no setor saúde através do General Agreement on Trade in Services (GATS) e o paradoxo existente, no próprio acordo, entre a interdependência e a soberania dos países. Um desafio a ser enfrentado nos processos de negociação internacional que determinam os mecanismos comerciais, através dos quais se dão as transações em serviços.

Por último, tendo como referência o Relatório Mundial de Saúde 2006 da OMS, esboçamos as perspectivas de enfrentamento da crise global da saúde, através de estratégias políticas voltadas a uma melhor distribuição internacional da força de trabalho.

Este trabalho foi apresentado na comunicação coordenada sobre regulação profissional do $11^{\circ}$ Congresso Internacional de Saúde Pública / $8^{\circ}$ Congresso Brasileiro de Saúde Pública, realizado no Rio de Janeiro em 2006. 


\section{Relevância do tema recursos humanos na agenda política global e nas prioridades para o setor saúde}

A internacionalização econômica, em função da distribuição heterogênea das riquezas, produziu tamanha desigualdade entre os países que os patamares de pobreza atingiram, em um conjunto majoritário de nações (África Sub-Saariana), níveis alarmantes; correspondendo a dois terços da população mundial. A crise atual na saúde, traduzida como desigualdade global em saúde, é consensualmente relacionada a esse empobrecimento, colocando entre as metas internacionais de desenvolvimento a redução da pobreza desses países. Para o alcance dessas metas, o setor ocupa posição de destaque, com prioridade no desenvolvimento de recursos humanos (PIERANTONI; VARELLA; FRANÇA, 2004).

O processo de globalização ocorrido nas últimas décadas trouxe novas formas de organização do Estado (o Estado mínimo). Não comprometido com a produção - apenas com a regulação - tem-se mostrado deficiente em função da baixa capacidade institucional para a formulação de políticas específicas de RHS. Além de empregar cada vez menos, passou a exigir novos patamares de qualificação. A repercussão dessa realidade no setor saúde é dramática, embora seja destinado o equivalente a mais de $50 \%$ do orçamento à remuneração de pessoal (ZURN; DAL POZ; ADAMS, 2003). Em geral, nos países de baixa renda, os gastos com salários de trabalhadores da saúde são superiores a dois terços do orçamento da saúde pública. Por exemplo, na República Dominicana, o gasto é de 67\% e no Equador, 72\%. Em alguns países, chegam a alcançar 75\% (SANDERS; LLOYD, 2005).

Considerando RHS a base de todas as intervenções do sistema de saúde, pode-se destacar que um dos requerimentos para a resolução da crise setorial seria equacionar a relação entre o funcionamento do sistema de saúde e a força de trabalho disponível.

O Relatório Mundial de Saúde de 2000 realçou a contribuição fundamental dos sistemas de saúde para melhorar a saúde global, e já mencionava a preocupação com as necessidades de recursos humanos, ressaltando que o desempenho dos sistemas de saúde ${ }^{1}$ depende definitivamente de conhecimento, experiência e motivação das pessoas responsáveis pelo provimento de serviços (DAL POZ et al., 2002).

Apesar da reconhecida importância da força de trabalho na dinâmica dos serviços de saúde, a negligência sistemática com as políticas necessárias ao desenvolvimento de recursos humanos conduziu a um cenário internacional desfavorável. Destaca-se o dilema dos sistemas de saúde dos países africanos, 
onde se concentram $25 \%$ da carga de doenças do mundo, contando, no entanto, com $1,3 \%$ dos recursos humanos existentes.

Uma força tarefa internacional foi convocada pela OMS para identificar prioridades, propor estratégias de aumento de recursos, e gerar uniformidade de opiniōes sobre a condução das mudanças; ou seja, uma agenda de sugestôes e informaçôes com o objetivo de criar possibilidades para que as reformas alcancem seus objetivos políticos essenciais, nesse novo milênio (TRAVIS et al., 2004).

A análise dos recursos humanos no setor saúde mostra a necessidade de melhorias quantitativas e qualitativas nas dimensões funcional, institucional e política (MARTINEZ; MARTINEAU, 1998), demandando mudanças indispensáveis no planejamento, gestão e desenvolvimento da força de trabalho no interior dos sistemas nacionais de saúde.

O enfrentamento do quadro de iniqüidade na distribuição da força de trabalho revela-se como prioridade para a resolução dos problemas de saúde global. A migração internacional de profissionais de saúde representa um dos principais fatores de desequilíbrio, enfatizando a relevância do tema RHS na agenda global e conquistando papel privilegiado em foros de saúde internacional.

\section{A força de trabalho em saúde no mundo atual: desequilíbrio, desigualdades e migração}

O desequilíbrio na força de trabalho em saúde é atualmente a maior preocupação e o maior desafio para os políticos do setor. Economicamente, esse desequilíbrio entre oferta e demanda de profissionais depende das condições de mercado. Num mercado competitivo, o desequilíbrio é dinâmico e reage rapidamente de acordo com a demanda, sendo, portanto, temporário. Se a oferta não oscila, o desequilíbrio é estático e, conseqüentemente, permanente. Nesse sentido, uma das questões chaves para se analisar o desequilíbrio da força de trabalho é identificar se o mesmo é temporário ou permanente.

Alguns autores classificam os desequilíbrios da força de trabalho de acordo com: as diferenças geográficas entre áreas rurais e urbanas e entre regiōes pobres e ricas; a escassez de médicos e enfermeiras ou de especialistas em determinadas áreas; as diferenças existentes nas instituições ou entre serviços e as disparidades entre a força de trabalho masculina/feminina (ZURN et al., 2004). Existe uma estimativa de 100 milhões de profissionais de saúde em todo o mundo, dos quais cerca de 75 
milhões são considerados incontáveis, como é o caso dos curandeiros e agentes comunitários. Em 2000, a OMS estimou um universo com 9 milhões de médicos e 15 milhōes de enfermeiras e auxiliares de enfermagem (SANDERS; LLOYD, 2005).

Tanto em países desenvolvidos quanto naqueles em desenvolvimento ocorre maior concentração de médicos nas áreas urbanas, em prejuízo das áreas rurais. Dentre os exemplos dessa má distribuição geográfica da força de trabalho em saúde está o caso de Manágua, capital da Nicarágua, que tem para um quinto da população a metade da força de trabalho disponível. Em Bangladesh, 35\% dos médicos e 30\% das enfermeiras em serviços de saúde localizam-se em quatro cidades metropolitanas, onde vivem apenas $14,5 \%$ da população. Esse padrão de concentração de países em desenvolvimento corresponde, como veremos, a um quadro bastante dramático de desequilíbrio e desigualdade entre os países (SANDERS; LLOYD, 2005).

Na perspectiva internacional, o ponto central da análise da distribuição da força de trabalho em saúde gira em torno da desigualdade e do desequilíbrio permanente, entre os sistemas de saúde africanos e o resto do mundo. Na África do Sul, a proporção é de um trabalhador para mil pessoas, enquanto que na Europa e América do Norte, é de 10 profissionais para mil pessoas. Nos países da África existem hoje menos trabalhadores em saúde do que há 30 anos, apesar de a população atual ter aumentado e, conseqüentemente, suas necessidades (SANDERS; LLOYD, 2005).

Alguns estudos voltados para o alcance das metas internacionais da saúde na próxima década demonstram a dimensão do problema quando fazem referência a uma densidade mínima necessária de 2,5 profissionais para cada mil habitantes. Ao mesmo tempo, apontam a existência de 75 países com 2,5 milhões de habitantes abaixo desse patamar mínimo, 45 dos quais são da África Sub-Saariana, localizando-se os 30 restantes na Ásia e América Latina. Além disso, demonstram, através de comparação entre países, que as mais altas taxas de mortalidade infantil estão nesses países com baixa densidade de profissionais de saúde - uma dupla crise: taxas crescentes de mortalidade e sistemas de saúde deficientes (RESUMEN EJECUTIVO, 2004).

Dentre os fatores que contribuem para esse desequilíbrio na densidade da força de trabalho, destacam-se: a demanda por trabalhadores em saúde; a produção de profissionais; o desempenho dos sistemas de saúde nacionais; as políticas de saúde regionais, nacionais e internacionais; as fontes de recursos; além de fatores econômicos, culturais, geográficos, sociodemográficos e políticos (figura 1). 
Como vemos, a figura 1 evidencia a complexidade de fatores envolvidos de forma direta ou indireta, tanto local quanto globalmente, com o desequilíbrio da força de trabalho em saúde e que funcionam como referência para a confecção de políticas de RHS. Mostra também que as políticas de outros países interferem no contexto de cada nação. É, portanto, clara a necessidade da abordagem do problema RHS em perspectiva global, sem deixar de lado as questôes internas de cada região.

\section{Migração internacional de profissionais de saúde}

A principal causa de desequilíbrio na distribuição mundial da força de trabalho em saúde, segundo a OMS, está no movimento migratório internacional de profissionais, de seus países de origem (em desenvolvimento) para países economicamente mais estáveis (HAGOPINA et al., 2004).

A migração de profissionais - carousel movement ${ }^{2}$ - não é um fato recente e pode ocorrer em várias direções. Enquanto nos anos 60 muitos médicos deixavam seus países de origem (desenvolvidos) para trabalhar em países em desenvolvimento, nos anos 90 houve uma inversão, profissionais de países em desenvolvimento começaram a buscar outros mercados de trabalho. $\mathrm{O}$ fato novo é que, entre outros fatores, a globalização da força de trabalho em saúde estimulou os indivíduos a exercerem a liberdade de mobilização, inclusive entre países desenvolvidos, tais como Austrália, Áustria, Bélgica, Dinamarca, entre outros.

Como exemplo dessa situação, temos a tabela 1 , com os percentuais de provisão de médicos estrangeiros em países selecionados entre os membros da Organização para Cooperação e Desenvolvimento Econômico (OCDE). No entanto, existem opiniōes diferentes sobre a contínua demanda de migração de profissionais de saúde. Uns a consideram como indicativo de falha no planejamento de RHS; outros a relacionam ao recrutamento deliberado de profissionais por parte dos países desenvolvidos, por razões econômicas.

Um estudo de cinco países industrializados revelou que, nos mesmos, o planejamento da força de trabalho parte do princípio de que oferecem serviços de saúde adequados, sem considerar o aumento da população com mais de 65 anos, que demanda cuidados específicos. Ocorre que, nesses países, a previsão das necessidades é equivocada e inadequada, porque parte do pressuposto de que o suprimento, particularmente de médicos, reflete a demanda. Se a previsão 
é falha, a quantidade de médicos, enfermeiras e auxiliares, é insuficiente (SANDERS; LLOYD, 2005).

Em quatro dos cinco países observa-se a utilização, por parte dos governos, do artifício de limitação financeira nas universidades, como forma de controle das escolas médicas e de outras áreas da saúde. Tais políticas resultam na produção insuficiente de profissionais, tendo como conseqüência a necessidade de recrutamento de força de trabalho de outros países. Por outro lado, considerar que a crise de RHS nos países em desenvolvimento é devido a essa baixa produção de profissionais especializados, não é o bastante. A produção adequada não resolveria a atual crise, uma vez que a mesma está relacionada também a outros fatores, dentro e fora dos sistemas de saúde, e que impulsionam a migração.

Essa política de captação e recrutamento de profissionais de saúde, por parte dos países desenvolvidos, associada à ausência de políticas claras de RHS nos países em desenvolvimento, tem contribuído para o aumento da migração de profissionais. A atual crise global da força de trabalho em saúde representa um grave complicador nas tentativas de recuperação dos sistemas de saúde, uma vez que o desenvolvimento dessas ações depende de força de trabalho qualificada, capaz de otimizar os recursos disponíveis, tanto financeiros quanto tecnológicos.

Inúmeras dificuldades ameaçam o planejamento e provimento dos sistemas públicos nacionais de saúde instituídos: baixos salários, pouca motivação e fraco desempenho do pessoal, distribuição desigual e iníqua da força de trabalho, irresponsabilidade e ausência de accountability. Além disso, a epidemia de HIV/ Aids, principalmente nos países da África, tem causado significativo impacto na força de trabalho em saúde, tanto pela morte dos profissionais, quanto pela resistência ou motivação ao trabalho, explicitada sob a forma de absenteísmo (MARTINEZ; MARTINEAU, 2002).

A ênfase curricular e os métodos de ensino nos países em desenvolvimento, inclusive na África do Sul, têm-se espelhado em treinamento de profissionais de saúde de países desenvolvidos. A tendência à especialização com recursos tecnológicos altamente sofisticados, existentes no setor privado e em grandes centros acadêmicos, tem facilitado a emigração de profissionais qualificados para países desenvolvidos do Reino Unido. Esse problema, associado à diminuição da alocação orçamentária para treinamento, tem afetado países como a África do Sul, que, embora produzam um número significativo de profissionais, não são capazes de 
retê-los. $\mathrm{O}$ treinamento é de longa duração e nem sempre é relevante às necessidades do país, o que compromete tanto a quantidade de profissionais treinados quanto a qualidade do treinamento (SANDERS; LLOYD, 2005).

Isso coloca em risco a viabilização dos sistemas de saúde dos países que se encontram com dificuldades de reter sua força de trabalho, requerendo especial atenção às regras de organização dos sistemas internos de saúde e à forma como os países administram o movimento migratório. A emigração de médicos especialistas de seus países se dá de duas formas: a saída temporária (mode 4 do GATS) ${ }^{3}$, que beneficia o país de origem com o retorno de médicos mais bem treinados e conhecedores de outras tecnologias, e as saídas permanentes, que significam uma transferência de capital humano.

Muitos médicos, ao encontrarem melhores situações salariais e de qualidade de vida nos países onde foram se capacitar, optam por não retornar ao país de origem. Ou pior, por estarem treinados para tecnologias que não encontram em seus países, sofrem problemas de readaptação. Essa situação, para os países que enfrentam problemas de diminuição da força de trabalho em saúde, conduz à deterioração das condições de trabalho, afetando a qualidade e o acesso ao cuidado em saúde.

A análise desenvolvida por Vujicic et al. (2004), dos fatores que influenciam na decisão individual de enfermeiras e médicos para mudarem de país, confirma que embora o salário seja a variável de maior influência no movimento, não é condição suficiente para reter o profissional, fato que coloca em questão a necessidade de melhorar as condições de trabalho e de vida desses profissionais em seus próprios países.

No encontro promovido pela Southern African Development Community (SADC), em 2001, para ministros da Saúde, foi notada a falta de vontade dos países desenvolvidos em modificar as políticas de recursos humanos de acordo com as demandas locais. Considerando que os países recebedores dessa mão-de-obra costumam ter políticas próprias de abertura de postos de trabalho, uma alternativa seria a criação de mecanismos de compensação aos países provedores dessa gama de trabalhadores. Como isso não acontece, a tendência é o aumento no volume de migração (SANDERS; LLOYD, 2005).

Como resultado dessa percepção, os países-membros da OCDE firmaram acordos internacionais para a regulação da migração de médicos entre eles. Um desses acordos é o General Agreement on Trade Services (GATS), que, pela análise de 
Forcier, Simoens e Giuffrida (2004) teve, até o momento, um impacto limitado, apesar de 29 países terem firmado compromissos na área de serviços de saúde. O GATS apenas estabelece que as regras de contratação e fixação desses profissionais devem ser transparentes e administradas de forma razoável, objetiva e imparcial.

\section{O papel das agências internacionais}

Durante a 2a Guerra Mundial, na Conferência de Bretton Woods, foram criadas instituições voltadas a uma nova ordem econômica. Imediatamente após a guerra, o governo norte-americano propôs a criação de um conjunto de organismos internacionais ligados às Nações Unidas, com o intuito de sustentar a segurança e a paz mundial (MATTOS, 2001).

Com a derrubada, nas últimas décadas, dos regimes coloniais e a queda das barreiras soviéticas ao mercado capitalista mundial, surgiu uma nova ordem global, pautada numa outra lógica, a qual Michael Hardt e Antonio Negri (2001) chamam de Império - um poder supremo que governa o mercado global e os circuitos globais de produção. Como conseqüência desse processo, a Comissão de Macroeconomia e Saúde tem dado particular importância à relação entre o grau de empobrecimento de dois terços da população mundial e a crise atual no setor, traduzida como desigualdade global em saúde (PIERANTONI; VARELLA; FRANÇA, 2004).

Em função disso, dentre as metas internacionais de desenvolvimento para o milênio, várias estão relacionadas à saúde. As agências doadoras dirigiram seus investimentos para a redução da pobreza dos países subdesenvolvidos, dando destaque ao setor saúde. Mediante a urgência de controle das doenças comunicáveis surgiram iniciativas globais, com foco na redução das doenças de alta prioridade como Aids, tuberculose, malária, além dos programas de imunização (MARTINEZ; MARTINEAU, 2002). Com isso, aumentou a doação de recursos por parte das agências, mas os recursos disponíveis não foram otimizados em seu uso, devido à escassez de profissionais. As expectativas para melhorar os mecanismos de distribuição dos recursos no setor público esbarraram na baixa capacidade institucional dos países subdesenvolvidos, principalmente em termos de implementação de políticas. Os graves e crônicos problemas de recursos humanos, tanto em saúde quanto em outros setores (MARTINEZ; MARTINEAU, 2002), comprometeram o potencial de acesso e recebimento dos novos recursos para provimento dos serviços de saúde. 
A convergência desses fatores direcionou o interesse dos doadores internacionais, trazendo o reconhecimento da necessidade de esforços contínuos no desenvolvimento de mecanismos mais eqüitativos e custo-efetivos. Ficou evidente a necessidade de mais investimento no fortalecimento dos sistemas de saúde dos países com grande contingente de pobreza, de forma a capacitá-los a prover cuidados de saúde à população. Isso representou uma mudança expressiva para o desenvolvimento internacional de RHS.

Segundo Dal Poz et al. (2002, p. 333), "algumas dessas agências têm-se destacado por seu papel na definição ou no desenvolvimento de políticas de recursos humanos em saúde". No entanto, a conduta das agências doadoras e os países receptores de ajuda têm tradicionalmente tratado o problema de forma ambivalente. O discurso de que RH é o mais importante "bem" dos sistemas de saúde apresenta enorme contraste com a atenção e volume de recursos efetivamente investidos.

As agências e doadores fazem parte do problema, pois consideram recursos humanos como gasto e não como investimento (SANDERS; LLOYD, 2004). A situação se agrava pelo fato de que o processo de negociação, na ajuda aos países receptores, ainda envolve questôes políticas macroeconômicas como uma précondição para o apoio efetivo (MARTINEZ; MARTINEAU, 2002).

A complexidade do processo de globalização das atividades de saúde está trazendo, no entanto, uma mudança na lógica das intervenções internacionais, ou seja, uma redefinição no papel dos doadores, conforme pode ser observado pela atuação de agências que se destacaram nesse âmbito.

\section{A Organização Mundial da Saúde}

A Organização Mundial da Saúde (OMS) nasceu no dia 7 de abril de 1948, em torno da ONU, como agência especializada para a saúde. Ela era inicialmente "estável e pragmática”, dominada por profissionais médicos, com programas verticais orientados para as doenças (DAL POZ et al., 2002, p. 333).

Com o tempo, a OMS passou a influenciar, monitorar e avaliar as políticas de saúde em todo o mundo, além de oferecer cooperação técnica e científica aos paísesmembros, como estratégia de aprimoramento dos sistemas nacionais de saúde (MATTOS, 2001). Em 2000, a OMS criou um grupo de trabalho para discutir as questôes estratégicas da força de trabalho em saúde, que resultou no seminário 
"Questões Estratégicas Globais da Força de Trabalho em Saúde", permitindo a identificação de áreas prioritárias de intervenção para melhorar o RHS.

A OMS reconheceu que a existência e a qualidade de serviços para promoção de saúde, prevenção de doenças ou para a cura e reabilitação depende do conhecimento, experiências e motivação dos RHS. Atualmente, defende que os países devem assegurar a seus sistemas de saúde um número adequado de provedores de serviços com experiência para atender às necessidades locais. Assim, a OMS colabora com seus 192 Estados-Membros no fortalecimento da capacidade de planejamento, educação e gestão da força de trabalho em saúde. Oferece suporte para o desenvolvimento de políticas de força de trabalho relacionadas às políticas de saúde global; avalia o número e a natureza dos provedores de serviços de saúde necessários para o atendimento das prioridades em saúde; explora opções políticas para recrutamento, administração e retenção da força de trabalho em saúde em mercados de trabalho variados.

Em 2006, o dia 7 de abril, Dia Mundial da Saúde, foi dedicado à valorização da força de trabalho em saúde como estratégia para desenvolvimento do setor. Nesse dia, centenas de organizaçóes realizaram, no mundo inteiro, eventos para atrair a atenção para essa crise global e comemorar a dignidade e valor dos trabalhadores da saúde. O dia foi aproveitado para o lançamento do Relatório Mundial de Saúde 2006 da OMS.

\section{Acordo Geral de Comércio em Serviços (GATS): o paradoxo entre a interdependência e a soberania dos países}

A resolução dos problemas de saúde global depende de um melhor aproveitamento das oportunidades trazidas pelo processo de globalização das trocas comerciais e culturais. As medidas que a saúde pública precisa adotar para evitar doenças e promover saúde têm como eixo de articulação mecanismos comerciais regionais e nacionais, mas também, internacionais. É importante deixar claro que o que interessa ao setor saúde é liberar as barreiras técnicas, concentrando, entretanto, sua atenção nas situações que possam colocar a saúde em risco. Porém, não se pode deixar de admitir que as negociaçôes são dependentes da liberalização comercial.

Fortuitamente, a tomada de consciência, por parte dos países desenvolvidos, da ameaça que representam o comércio e o fluxo de pessoas na propagação de epidemias, vem colocando os benefícios da saúde acima da conveniência comercial, 
e daí os esforços de investimento. É a partir dessa concepção que surgem os interesses da liberalização na saúde pública voltados à remoção de obstáculos para o comércio de bens e serviços. A criação do GATS (General Agreement of Trade in Services) é, então, uma resposta a essa demanda.

Durante a rodada de negociações do Uruguai, em 1994, o tradicional sistema multilateral de regulação comercial entre países (GATT) ${ }^{4}$ foi substituído por uma organização internacional, a Organização Mundial do Comércio (OMC). Na mesma ocasião, sob os auspícios da OMC, foi criado o Acordo Geral de Comércio sobre Serviços (GATS) ${ }^{5}$, efetivado em 1995, oferecendo a condição legal multilateral para a liberalização (ou quebra de barreiras) do comércio internacional em serviços.

O GATS representa para os países exportadores a oportunidade de gerar ganhos em moeda estrangeira e aumentar os recursos para a saúde e com isso, melhorar conhecimento, qualidade e infra-estrutura. Para os países importadores - em desenvolvimento - traz a possibilidade de superar a falta de recursos humanos e físicos, bem como receber tratamento diferenciado no processo de liberalização do comércio em serviços de saúde.

Sendo um acordo que trata da quebra (ou redução) de barreiras para que o mecanismo comercial possa atuar, o GATS significa, por um lado, compromissos específicos entre os países, garantindo acesso ao mercado sem qualquer tipo de quota ou restrições similares; por outro, tratamento nacional, ou seja, prestadores de serviços estrangeiros não podem ser tratados de maneira menos favorável que os nacionais. Trata-se de um acordo complexo, pois cria novas regras para serviços a partir de leis internacionais de comércio já existentes, sob as quais alguns países têm cada vez menor poder de regular os fluxos comerciais e de impor sua autoridade sobre a economia. Assim, a soberania política das nações está comprometida: países desenvolvidos subordinam os países em desenvolvimento.

Ocorre que, na globalização, se por um lado os fatores primários de produção e troca - dinheiro, tecnologia, pessoas e bens - estão acima das fronteiras nacionais, por outro, a responsabilidade das ações de saúde é de soberania nacional. Então, em relação ao acordo, o que surge como problema para os sanitaristas não é mais sua pertinência, mas a forma como o GATS afeta os serviços relacionados à saúde e às políticas nacionais de saúde. Isso sem desconsiderar que a nova divisão internacional do trabalho estabeleceu uma concorrência desleal entre países centrais, semiperiféricos e periféricos ${ }^{6}$, produzindo acentuada desigualdade política, econômica e social. 
O primeiro problema está no fato de que o acordo é acusado de interferir na liberdade com que os países elaboram suas políticas, estruturam seus sistemas de saúde e regulam seus serviços, ameaçando orçamento, minando a regulação doméstica e dificultando os governos na manutenção da saúde pública. Nesse sentido, a questão central é se o abastecimento dos serviços públicos de saúde está ou não excluído do acordo e de suas regras. A forma vaga como a questão é colocada no artigo $1(\$ 3)^{7}$ do GATS deixa em aberto a possibilidade de que o suprimento de serviços públicos de saúde seja excluído do acordo.

Além disso, o impacto do GATS e das políticas macroeconômicas internacionais de saúde influenciam nas políticas nacionais de desenvolvimento de RHS, interferindo claramente na saída de profissionais de serviços públicos para o setor privado, estimulando a permanente migração de pessoal qualificado (brain drain) de países em desenvolvimento para países desenvolvidos. Isso produz escassez de profissionais nos países em desenvolvimento e agrava a enorme desigualdade na distribuição da força de trabalho existente entre os países da África e o resto do mundo (SANDERS; LLOYD, 2005).

Como já referido, no Reino Unido, Canadá e EUA, a subprodução de trabalhadores de saúde e a grande demanda de saúde imposta pela população idosa são as causas das estratégias agressivas de recrutamento. Práticas antiéticas, tais como a redução das exigências na imigração, no visto de entrada, na permissão de trabalho, em garantias de reembolso e outros fatores chaves, causam impacto no comércio internacional e configuram poderoso estímulo ao processo migratório.

Nos países em desenvolvimento, por outro lado, outros fatores alimentam o movimento de cruzamento de fronteiras: desníveis salariais entre os países, procura por melhores condiçôes e padrões de vida e demanda/oferta desequilibrada entre países exportadores e importadores fazem com que mesmo países que produzem boa quantidade de profissionais de saúde e staff qualificado sejam muitas vezes incapazes de retê-los.

O problema maior está no fato de que os países exportadores e importadores interpretam de formas diferentes o mode 4 do GATS $^{8}$, que se refere ao movimento temporário de profissionais (médicos e enfermeiras trabalhando em outros países). Em geral, esse item é, erroneamente, compreendido como exportação de recursos humanos: alguns países encorajam a saída e outros criam barreiras. 
Enfim, o GATS, ao provocar essa tensão entre a interdependência dos países e a manutenção de suas soberanias nacionais, vem sendo apontado como um acordo paradoxal. Se, por um lado, enfraquece o exercício da soberania em relação aos objetivos da saúde, por outro, respeita a soberania sanitária, por sua flexibilidade. Isso permite que cada membro da OMC configure suas obrigações de acordo com interesses e necessidades nacionais.

A complexidade do mundo globalizado deve ser considerada para que se possa compreender, negociar e superar a tensão existente entre a manutenção da autonomia dos países e a internacionalização de atividades econômicas, dentre as quais, as atividades de saúde. Se a internacionalização de atividades de saúde se faz através de mecanismos comerciais definidos pelos termos do GATS, o desafio da eqüidade, através do equilíbrio e distribuição da força de trabalho (meta principal das açôes de saúde), está no melhor aproveitamento, por parte dos políticos da saúde, das oportunidades de negociação.

\section{Cenários futuros}

Delineia-se, portanto, um quadro de extrema urgência: um terço da população mundial vive em condiçôes miseráveis, submetidas à fome e à doença; doenças infecciosas e complicações da gravidez e parto causam, em 57 países em desenvolvimento, mais de um milhão de mortes a cada ano; 1,3 bilhôes de pessoas não têm acesso aos mais básicos cuidados de saúde, por falta absoluta de profissionais de saúde.

Embora a escassez de profissionais de saúde seja global, a situação na África Sub-Saariana é extremamente grave. Face às dificuldades econômicas dos países, os trabalhadores da saúde vivem profundas inquietaçôes sociais, tanto pela pobreza quanto pela ameaça de vida pela epidemia de HIV/AIDS. Com isso, o brain drain de profissionais qualificados para países ricos, em busca de melhores salários e melhores condições de vida, aumenta a cada dia.

Esse cenário mundial denuncia sérios obstáculos ao desenvolvimento de sistemas de saúde nacionais capazes de responder efetivamente aos principais desafios da saúde: intervenções como imunização infantil, assistência à gravidez e parto ou tratamento de HIV/Aids, malária, tuberculose, gripe aviária, entre outros.

Tendo como referência esse contexto, a OMS apresentou oficialmente o Relatório Mundial de Saúde 2006, no dia 07 de abril (Dia Mundial da Saúde), dando 
início à Década da Força de Trabalho em Saúde, 2006-2015. Na mensagem de abertura do relatório, o diretor geral, Dr. Lee Jong-Wook, apoiado por líderes e gestores de todo o mundo, enfatizou a importância dos RHS como fundamental para o bem-estar e sobrevivência das populações, sendo a África exemplo inquestionável dessa situação. Colocou como meta principal das ações em saúde o alcance da eqüidade e, como maior desafio, a má distribuição da força de trabalho.

Reafirmou como causas a migração, a doença e morte dos trabalhadores, bem como a extrema dificuldade de treinamento e retenção de trabalhadores. Apesar de reconhecer a falta de consenso, destacou a necessidade de uma cadeia de cooperação e divisão de responsabilidades: entre os setores público e privado, no tocante às instituições de educação; entre aqueles que planejam e influenciam os profissionais da saúde; e entre os que têm o compromisso financeiro de garantir as condições gerais do RHS.

Considerando que, na racionalidade do modelo capitalista, as forças de mercado dos países desenvolvidos subordinam os países em desenvolvimento, o desafio está em encontrar alternativas para além dos acordos internacionais voltados para o comércio. Isto significa caminhar no sentido da justiça social, respeitando peculiaridades econômicas e culturais.

Nesse sentido, abrem-se possibilidades para que os governos dos países em desenvolvimento encontrem soluções locais para a formação e retenção de recursos humanos. Dentre estas, antecipam-se: administrar a migração de trabalhadores de saúde dentro das estruturas nacional e regional; estreitar as relaçôes de trabalho entre governos nacionais, prestadores de serviços de saúde e profissionais liberais.

\section{Conclusão}

A situação desfavorável da África, abordada neste trabalho, está intimamente relacionada ao processo de globalização. Não se trata de uma questão conjuntural e sim de uma condição estrutural. Se não houver desenvolvimento dos países africanos como um todo, que impulsione a produção de riquezas, a situação será cada vez mais sombria. Não adianta pensar em metas para a saúde se estas não estiverem articuladas ao desenvolvimento.

É crucial a necessidade de uma intervenção capaz de causar impacto significativo na qualidade dos cuidados em saúde, considerando as possibilidades de treinamento adequado, sobretudo nos países africanos. Nesse sentido, configura-se como uma 
alternativa promissora a capacitação, em larga escala, de trabalhadores de nível médio e de agentes comunitários, com menor tendência à migração.

A experiência no Brasil ${ }^{9}$ com o Projeto de Profissionalização de Trabalhadores da Área de Enfermagem (PROFAE), para auxiliares e técnicos de enfermagem, vem sendo considerada uma boa resposta no enfrentamento da baixa qualificação da força de trabalho. A qualificação profissional da primeira turma de auxiliar de enfermagem se deu em 2000. A primeira fase foi de investimento maciço na formação de auxiliares, e a segunda voltou-se para a capacitação de técnicos. Em 2005, o PROFAE já tinha alcançado 89,6\% da meta proposta (SÓRIO, 2005), revelando-se uma alternativa para os países africanos, consideradas e respeitadas as peculiaridades locais.

A preocupação com a migração internacional tem levado grupos como a Commonwealth Secretariat ${ }^{10}$ a desenvolver movimentos que promovam práticas éticas para o recrutamento internacional. Um código com regras para os processos de recrutamento e migração foi acordado entre os países-membros da comunidade. Esse Código aplica os princípios de transparência, justiça e mutualidade de benefícios entre países, bem como entre os profissionais migrantes e recrutadores. Estabelece ainda proposta de reciprocidade dos países recrutadores aos países fontes, seja pela transferência de tecnologia ou pela ajuda técnica e financeira, de acordo com interesses de cada país. Iniciativas como estas devem ser fortalecidas e ampliadas.

Embora a OCDE já tenha definido as metas de desenvolvimento para o novo milênio, e a OMS já tenha apresentado o Relatório Mundial de Saúde 2006, com propostas que envolvem compromissos, planejamento, investimentos em áreas prioritárias e metas a serem alcançadas na próxima década, a expectativa está colocada na eficiência, prontidão e eficácia dessas ações.

Se, por um lado, a meta principal das ações de saúde é alcançar a eqüidade, por outro, a força de trabalho é a personificação dos valores dos sistemas de saúde, ou seja, o elo humano entre tecnologia, conhecimento e ação na saúde. Os maiores desafios estão no fortalecimento dos serviços de saúde, na capacitação profissional e na distribuição geográfica da força de trabalho, dentro e entre os países.

A superação desses desafios passa pelo desenvolvimento de políticas que definam métodos de recrutamento de profissionais e estratégias capazes de atrair, reter e distribuir eqüitativamente a força de trabalho. Isso requer, por parte das agências internacionais, um posicionamento ético, no sentido de fortalecer as nações em 
suas transações comerciais. A implementação da eqüidade da força de trabalho em saúde depende, portanto, das estratégias de aproveitamento por parte dos países em desenvolvimento, e do potencial de articulação oferecido pelo GATS nas negociações internacionais de RHS.

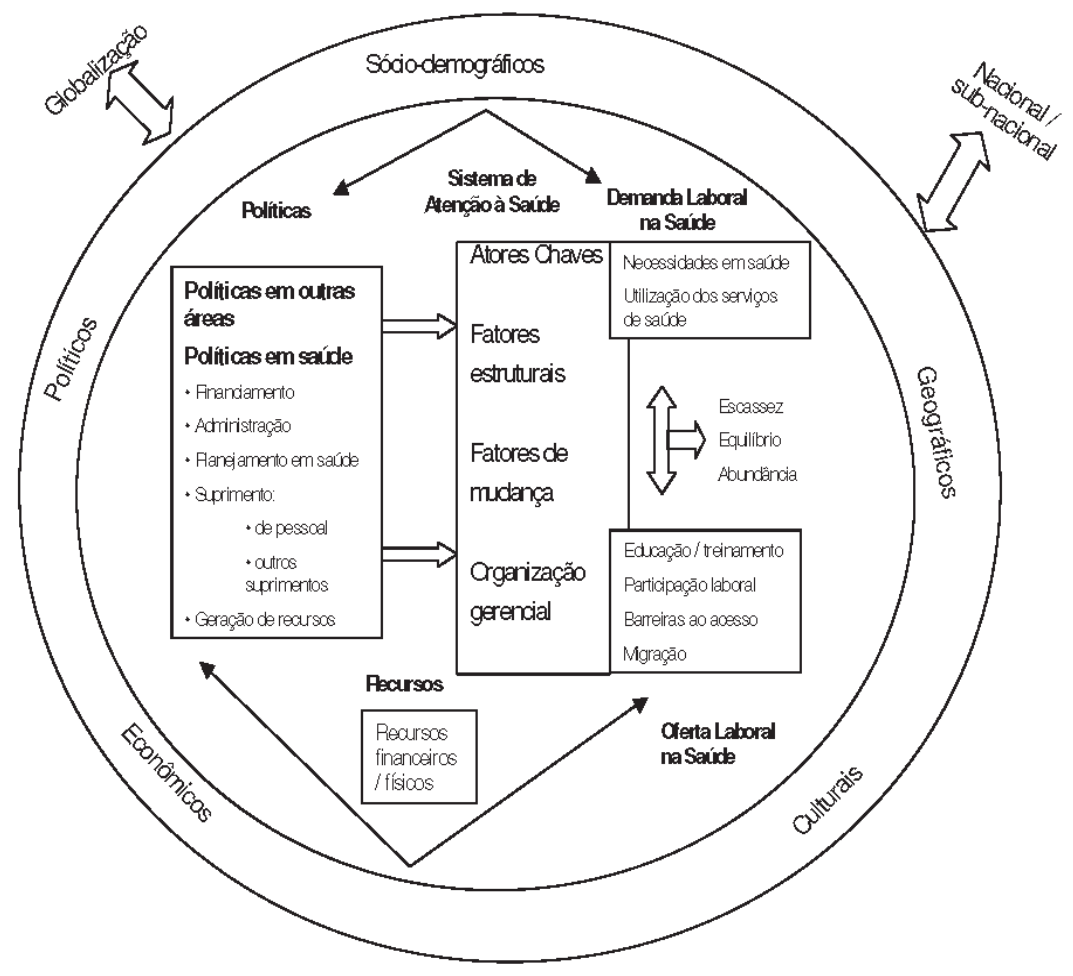

Figura 1

Fonte: Mercer et al. (2003) apud Pierantoni, Varella e França (2004). 
TABELA 1

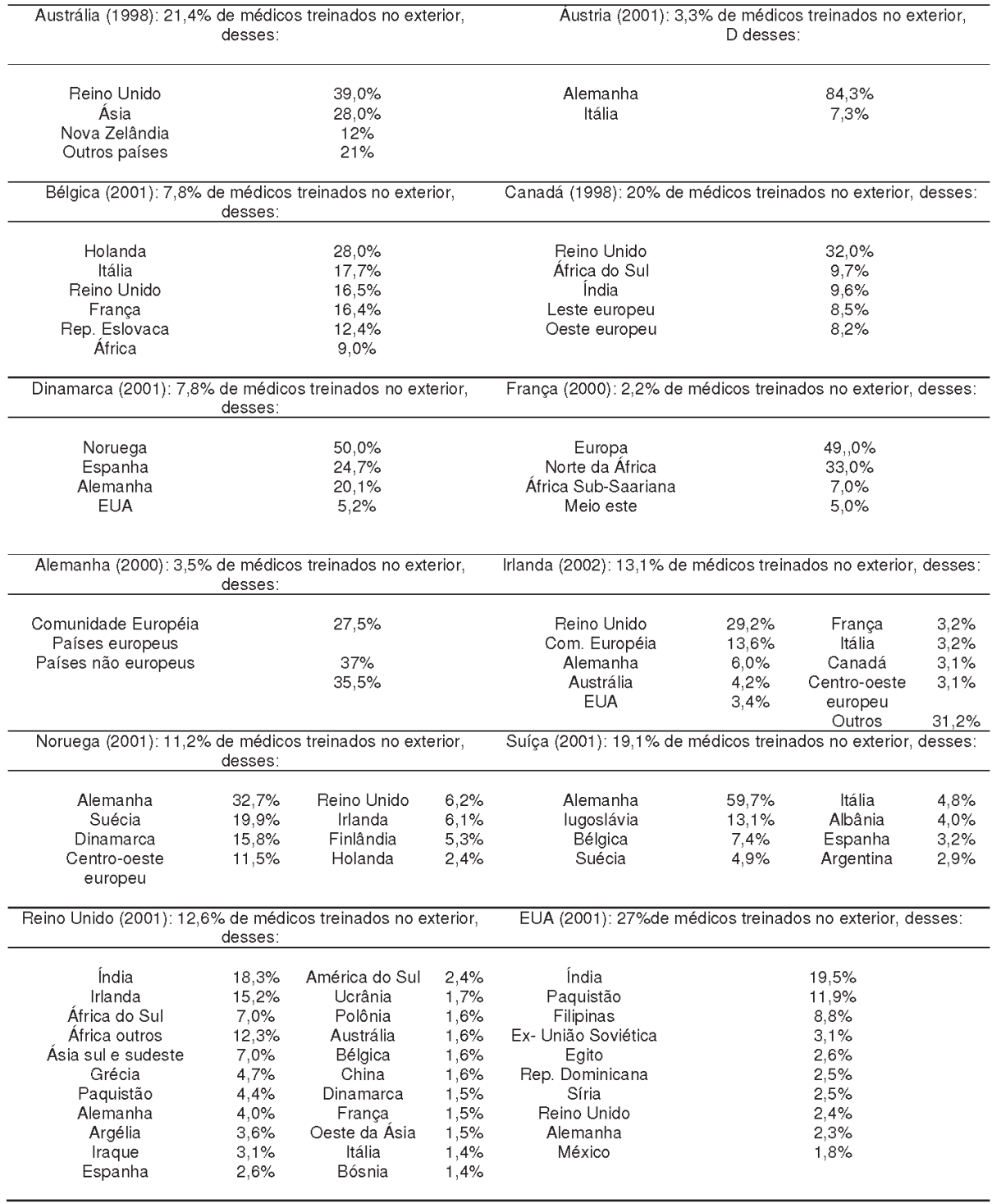

Fonte: Forcier, Simoens e Giuffrida (2004). Livre adaptação das autoras.

\section{Referências}

BELSKY, L. et al. The General Agreement on Trade in Services: implications for health policymakers. Health Affairs. Chevy Chase, v. 23, n. 3, p. 137-146, May/Jun 2004. 
DAL POZ, M. et al. Agenda das organizaçōes internacionais para o desenvolvimento de RH em saúde: novos problemas e soluções. In: NEGRI, B.; FARIA, R.; VIANA, A. L. (Orgs.). Recursos humanos em saúde: política, desenvolvimento e mercado de trabalho. Campinas: NEPP, 2002. p. 323-342.

DEPARTMENT FOR INTERNATIONAL DEVELOPMENT. Mission statement. Disponível em http://www.dfid.gov.uk/aboutdfid. Acesso em: 16 mar. 2006.

DRAGER, N.; FIDLER, D. P. Managing liberalization of trade in services from a health policy perspective. Gats and Health Related Services. Disponível em www.who.int/trade/en. Acesso em: mar. 2006.

DUSSAULT, G.; DUBOIS, C. Human resources for health policies: a critical component in health policies. Human Resources for Health 2003, 1:1. Disponível em http://www.human-resourceshealth.com/content/1/1/1. Acessado em: 12 dez. 2005.

FORCIER, M. B.; SIMOENS, S.; GIUFFRIDA, A. Impact, regulation and health policy implications of physician migration in OECD countries. Human Resources for Health, 2004. Disponível em http:/ /www.human-resources-health.com/content/2/1/12. Acesso em: 12 dez. 2005.

HAGOPINA, A. et al. The migration of physicians from sub-Saharan Africa to the United States of America: measures of the African brain drain. Human Resources for Health, 2004. Disponível em: http://www.human-resources-health.com/content/2/1/17. Acesso em: 12 dez. 2005.

HARDT, M.; NEGRI, A. Império. Rio de Janeiro: Record, 2001.

LA ORGANIZACIÓN INTERNACIONAL DEL TRABAJO. Disponível em: http:// www.ilo.org/public/spanish/about/index.htm. Acesso em: 03 mar. 2006.

MARTINEZ, J.; MARTINEAU, T. Human resources in the health sector: an international perspective. 2002. Disponível em: http:/www.healthsystemsrc.org. Acesso em: dez. 2005.

. Rethinking Human Resources: An Agenda for the Millennium. Health Policy and Planning, v. 13, n. 4, p. 345-358, 1998.

MATTOS, R. A. As Agências internacionais e as políticas de saúde nos anos 90: um panorama geral da oferta de idéias. Ciências e Saúde Coletiva, v. 6, n. 2, p. 377-389, 2001.

NARASIMHAN, V. et al. Responding to the global human resources crisis. The Lancet, v. 363, May 1, 2004. Disponível em: http://www.thelancet.com. Acesso em: nov. 2005.

OLLILA, E. Global health priorities: priorities of the wealthy? Globalization and Health 2005. Disponível em: http://www.globalizationandhealth.com/content/1/1/6. Acesso em: nov. 2005.

ORGANIZATION FORECONOMICCO-OPERATION AND DEVELOPMENT. Disponível em: http://www.oecd.org/document/54/0,2340,en26493462919350941111,00.html. Acesso em: 13 mar. 2006. 
_-_-_-_. About OECD. Disponível em: http://www.oecd.org/about/ 0,2337,en264920118511111,00.html. Acesso em 16 mar. 2006.

PORTAL DA SAÚDE. Disponível em: http://www.saude.gov.br/saude. Acesso em: 13 mai 2006. . Ministério da Saúde. Portaria n. 1.262, de 15 de outubro de 1999. Cria o projeto de profissionalização dos trabalhadores na área de enfermagem. D.O.U., Brasília, DF, out. 1999. www.saude.am.gov.br/docs/dou0905.pdf. Acesso em: mar. 2006.

PIERANTONI, C.; VARELLA, T.; FRANÇA, T. Recursos humanos e gestão do trabalho em saúde: da teoria para a prática. In: BARROS, A. F. R. et al. (Orgs.). Observatório de Recursos Humanos em Saúde no Brasil: estudos e análises. Série B, v. 2. Brasília: Ministério da Saúde, 2004.

PROFAE. The assumptions, design and results of the impact evaluation of PROFAE on the quality of the health services. In: LIMA DE CASTRO J., (Ed.). PROFAE: Health professional education and citizenship. Brasilia: Ministry of Health, 2002, p. 149-163.

RESUMEN EJECUTIVO: Informe Estratégico de la Iniciativa de Aprendizaje Conjunta en Recursos Humanos para la Salud. Recursos Humanos para la Salud: Superemos la Crisis. Disponible em: http://www.globalhealthtrust.org. Acesso em: 27 nov. 2004.

SANDERS, D.; LLOYD, B. Human resources: international context. Health Systems Trust, South Africa. Chapter 6, p. 76-87, 2005.

SÓRIO, R. Profissionalização dos auxiliares de enfermagem do marco da reforma setorial em Brasil. Profesionalización de auxiliares de enfermería en América Latina. Edición Especial no 13. OPAS, Washington, D.C., 2005. Disponível em: http:/www.paho.org/Spanish/DPM/SHD/HR/ profesionaliz-enferm-alc.pdf. Acesso em: 13 maio 2006.

THEWORLD BANK. Key Topics. Disponível em: http://web.worldbank.org. Acesso em: 14 mar. 2006.

. Quiénes somos (Sobre nuestra institución). Disponível em: http://web.worldbank.org/ WBSITE/EXTERNAL/BANCOMUNDIAL/QUIENESSOMOS/0, , menuPK: 64058517 pagePK:64057857 piPK:64057865 theSitePK:263702,00.html. Acesso em: 14 mar. 2006.

THE WORLD HEALTH ORGANIZATION. What is the World Health Organization Doing? Disponível em: http://www.who.int/hrh/en/. Acesso em: 03 mar. 2006.

. The World Health Report 2000. What resources are needed? Disponível em: http:// www.who.int/whr/2000/en/whr00_ch4_en.pdf. Acesso em: 16 fev. 2006.

. The World Health Report 2006: working together for health. Disponível em: http:// www.who.int/whr/2006/en/. Acesso em: mar. 2006.

TRAVIS, P. et al. Overcoming health-systems constraints to achieve the millennium development goals. Lancet, v. 364, p. 900-06. Set 4, 2004. Disponível em http://www.thelancet.com. Acesso em: mar. 2006. 
VUJICIC, M. et al. The role of wages in the migration of health care professionals from developing countries. Human Resources for Health, 2004, v. 2, p. 3. Disponível em http://www.humanresources-health.com/content/2/1/3. Acesso em: 12 dez. 2005.

ZURN, P. et al. Imbalance in the health workforce. Human Resources for Health 2004, v. 2, p. 13. Disponível em http://www.human-resources-health.com/content/2/1/13. Acesso em: 12 dez. 2005.

ZURN, P.; DAL POZ, M. R.; ADAMS, O. L'Organisation Mondiale de la Santé et le Développement des Ressources Humaines du Systeme de Santé. Cah .Socio. Démo. Méd., v. 43, n. 3, p. 467-484, July-September 2003.

\section{Notas}

${ }^{1}$ Dal Poz (2002, p. 334) toma como referência a definição estratégica de Murray \& Frenck (2000) para dizer que "se deveria dar maior ênfase ao desenvolvimento dos sistemas de saúde, para oferecer maior eqüidade, aumentar a eficiência, responder às legítimas demandas da população e ser financiado de maneira socialmente justa”.

2 "Carousel movement", termo usado por Forcier, Simoens e Giuffrida (2004).

${ }^{3}$ Assunto desenvolvido no subtítulo GATS.

${ }^{4}$ GATT: General Agreement on Tariffs and Trade (1947).

${ }^{5}$ GATS: General Agreement on Trade in Services (1994).

${ }^{6}$ Pierantoni et al. In "Recursos humanos e gestão do trabalho em saúde: da teoria para a prática" cita Pochmann (2001), que adota como enfoque teórico para a divisão da economia mundial agrupamentos de países. Países do centro capitalista: Áustria, Japão, Holanda, Estados Unidos, Inglaterra, entre outros. Países semiperiféricos: Austrália, Turquia, Portugal, Rússia, Brasil, Coréia, África do Sul, entre outros. Países periféricos: Zaire, Nigéria, Marrocos, Jamaica, Barbados, Indonésia, Peru, República Dominicana, entre outros.

${ }^{7}$ GATS: Article 1: \$3: A "service supplied in the exercise of governmental authority" means any service which is supplied neither on a commercial basis nor in competition with one or more service suppliers.

${ }^{8}$ General Agreement on Trade in Services (GATS): Mode 4: refers to the Temporary movement of natural persons.

${ }_{9}^{9}$ Ministério da Saúde, Portaria no 1.262 GM, de 15 de outubro de 1999. Disponível em: http:// www.portalsaude.gov.br. Com a meta de qualificar 225 mil auxiliares e 90 mil técnicos em enfermagem, o governo obteve financiamento do Banco Interamericano de Desenvolvimento (BID).

${ }^{10}$ Ver em Commonwealth Code of Practice for the International Recruitment of health Workers. Pre-WHA Meeting of Commonwealth Health Ministers, 2003, Genebra, 18 maio 2003. 


\section{Abstract}

\section{Workforce Distribution: Equity and} Negotiation

The significant existing disproportion in the density of human resources makes the equity of human resources distribution a strategic issue for possible solutions of health problems. This can explain the importance of the human resources issue in the global health agenda and its priority for the health sector. The policy of recruitment of health workers by developed countries as well as a lack of clear policies to prevent brain drain by developing countries are contributing migration factors. Under the leadership of WHO, some international agencies have been developing and subsidizing human health resources policies. However the existing paradox between the interdependency and sovereignty of countries requires an ethical and strategic standpoint in order to strengthen nations in their commercial dealings. Therefore one of the challenges to global health is in grabbing the opportunities offered by GATS for international human health resource negotiations.

> Key words: Equity; world distribution of human health resources; health workforce migration; international negotiation; GATS. 